\section{Analyzing the Growth of Magmatic Crystals - An Electron Microprobe Analysis Study}

\author{
Robert Sturm \\ Department of Materials Engineering and Physics \\ University of Salzburg, Austria \\ Robert.Sturm@sbg.ac.at
}

\section{Introduction}

Since the pioneering mineralogical and crystallographic studies of the 1960s and 1970s it has been regarded as a fundamental tenant of earth sciences that the growth of minerals, and especially of magmatic mineral phases, depends upon the physico-chemical state of the growth environment. Meanwhile, based on extensive

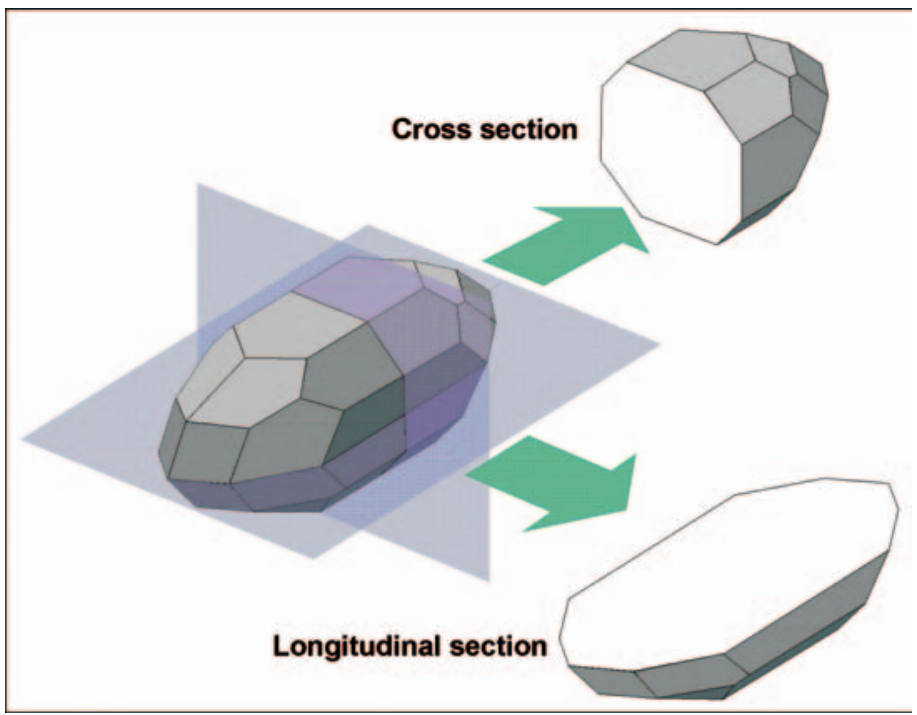

Fig. 1: Preparation of zircon crystals for growth analysis with the electron microprobe. Selected grains are cut either perpendicular or parallel to their crystallographic main axis. rock-forming processes ${ }^{(4)}$. A third reason underlining the scientific exclusiveness of zircon is its development of well recordable and easily distinguishable crystal shapes which, in most cases, are composed of two prisms and two pyramids (biprasmatic bipyramidal morphology).

A systematic empirical description of the various zircon shapes occurring in igneous rocks was carried out in the 1970s and 1980s, leading to the introduction of the so-called typology diagram ${ }^{(5)}$. This represents a graphical scheme containing all zircon morphologies described hitherto as a combination of the prism forms $\{100\},\{110\}$ and the pyramidal forms $\{101\}$, $\{211\} /\{311\}$. As deduced by an extensive statistical evaluation of different zircon populations, the predominance of certain forms mainly depends upon the chemical and thermal characteristics of the magmatic source, i.e. Al-rich magmas with lower temperature usually develop different crystal shapes than alkaline magmas with higher temperatures of formation. Hence, zircon was evaluated as a petrogenetic indicator bearing basic information of its source rock and even as a geothermometer having recorded the temperature during crystallization ${ }^{(6)}$.

From the 1960s to the 1980s, zircon morphology was mainly studied using various techniques of light microscopy. From the 1990s on, electron microscopic methods began to become widely utilized $^{(7,8)}$. These innovative and partly even revolutionary methodical approaches provided a direct insight into zircon crystal development, leading to a new understanding of the essential relationship between zircon growth and environmental chemistry ${ }^{(9)}$. Nowadays, electron microscopic analyses, including backscattered electron imaging and cathodoluminescence, have to be regarded as basic procedures to obtain advanced information concerning the important role of accessory zircon as a petrogenetic indicator.

\section{Electron microprobe analysis}

The electron microprobe represents a highly efficient tool empirical and experimental approaches, some factors controlling crystal growth and, as a consequence of that, crystal shape or morphology can be detected and documented ${ }^{(1,2)}$. Therefore, the chemistry and temperature of the growth environment, as well as its content of volatile phases, have been found to be key to understanding the crystallization processes.

Concerning the crystallization of mineral phases out of a magmatic source, accessory zircon has attracted a great deal of geoscientific attention in the past decades $^{(3)}$ due to several reasons. First, zircon is characterized by a somewhat ubiquitous occurrence, i.e. it can be separated from magmatic, metamorphic, and sedimentary rocks. In very exceptional cases, the accessory mineral can also be detected as a component of extraterrestrial rocks. Second, zircon exhibits a strong resistance to any processes in the earth's crust, thereby often being involved in several cycles of
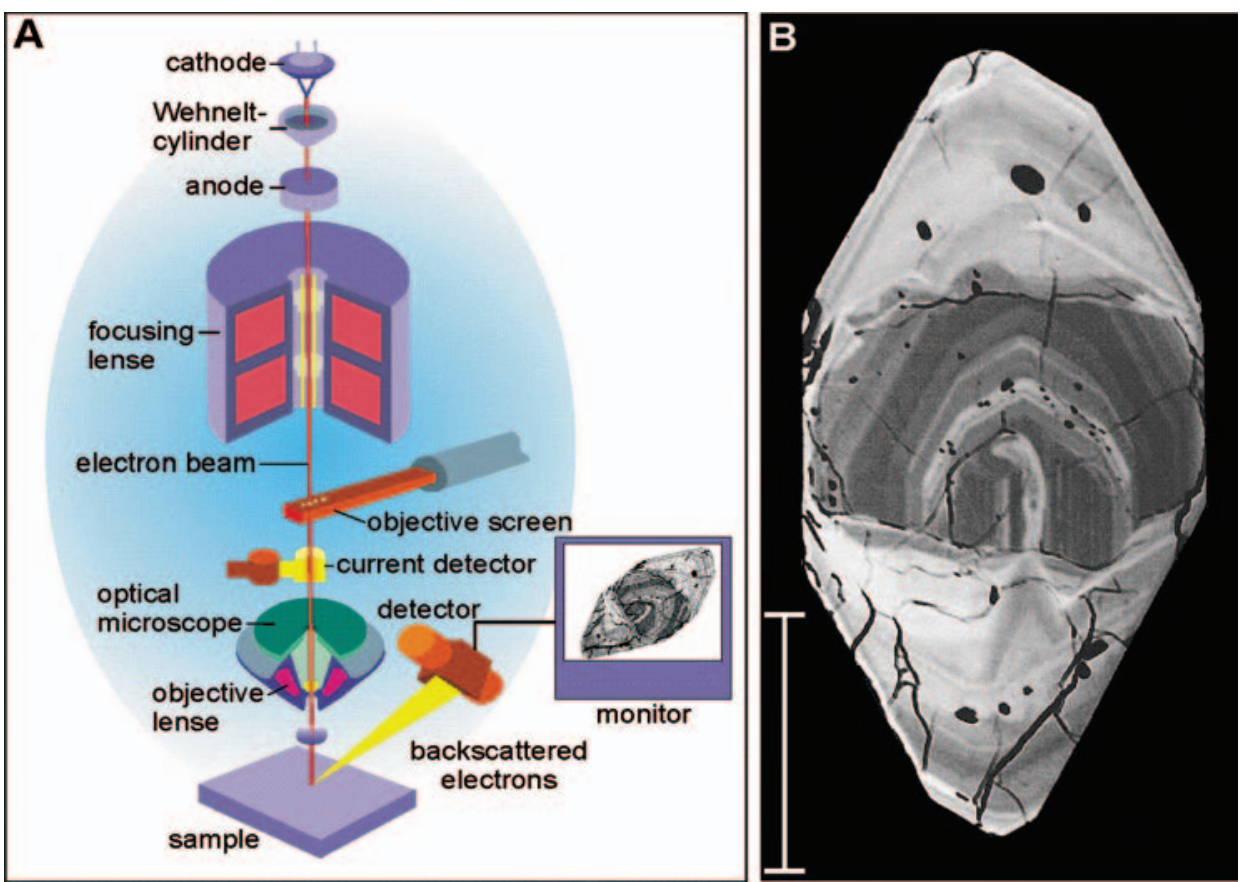

Fig. 2: A) Technical setup necessary for backscattered electron imaging of zircon crystal sections. B) Image of a zircon crystal with its typical pattern of dark and bright growth zones (bar: $50 \mu \mathrm{m}$ ). 
The State of the Art, Revolutionary

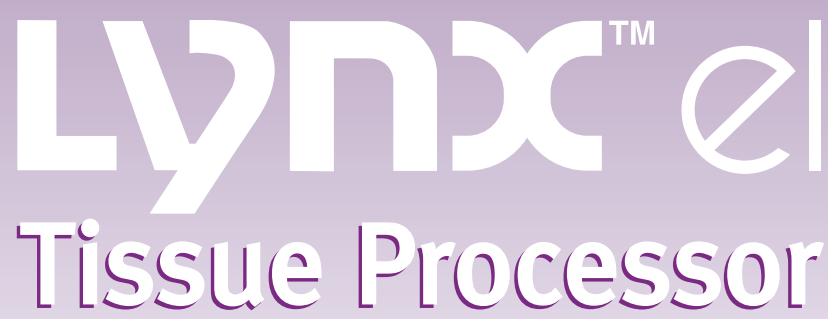

The EMS LMNX Automated Tissue Processor now made even better... for Electron Microscopy and Light Microscopy.

Dramatically reduce your sample preparation cost and time with improved reproducible results!!

The EMS LMNX allows for the processing of tissue all the way through $100 \%$ resin.

\section{Primary uses:}

- Ultrastructural Studies

- Extremely Hard Tissues - Undecalcified Bone

- High Resolution Light Microscopy

- Immunohistochemistry

- Dehydration for SEM

- Deparaffinization

- En-bloc Staining

- And Much More

This state of the art Automated Tissue Processor has many unique features making the unit the most versatile and reliable unit on the market at a very competitive price.

\section{Features:}

- Stainless Steel Working Surfaces

- Enclosed Benchtop Unit

- Reagent Turntable/ Max of 56 Specimens

- 20 Reagent Vials/Cycle

- Temp Range of $4^{\circ} \mathrm{C}-60^{\circ} \mathrm{C}$

- Built in Exhaust Fan

- Alarm Monitoring System

- Multiple Safety Features

- Battery Back Up

- Storage of 10 Programs/ Each with 20 Pre-programmable Steps

- Printer Output

- Delay Start of Programs

- And Much More...

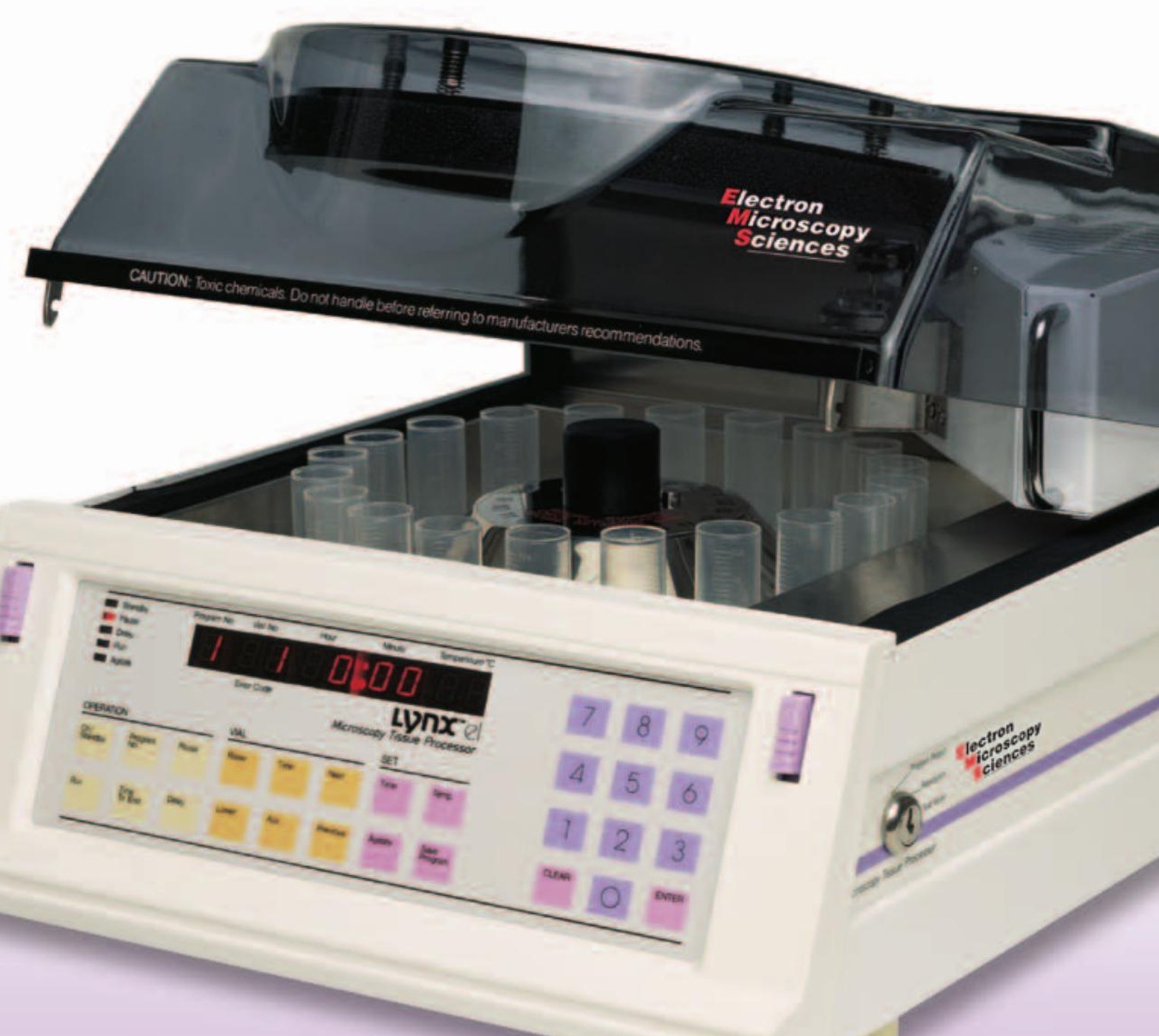

For more information or a complete brochure on the "LYNX" Automated Tissue Processor, please call or write us today.

\section{Electron Microscopy Sciences 1560 Industry Road P.O. Box 550 . Hatfield, PA 19440} tel: 2 15.4 I2.8400 - fax:2 I5.4 I2.8450 - email:sgkcck@aol.com - web:www.emsdiasum.com 



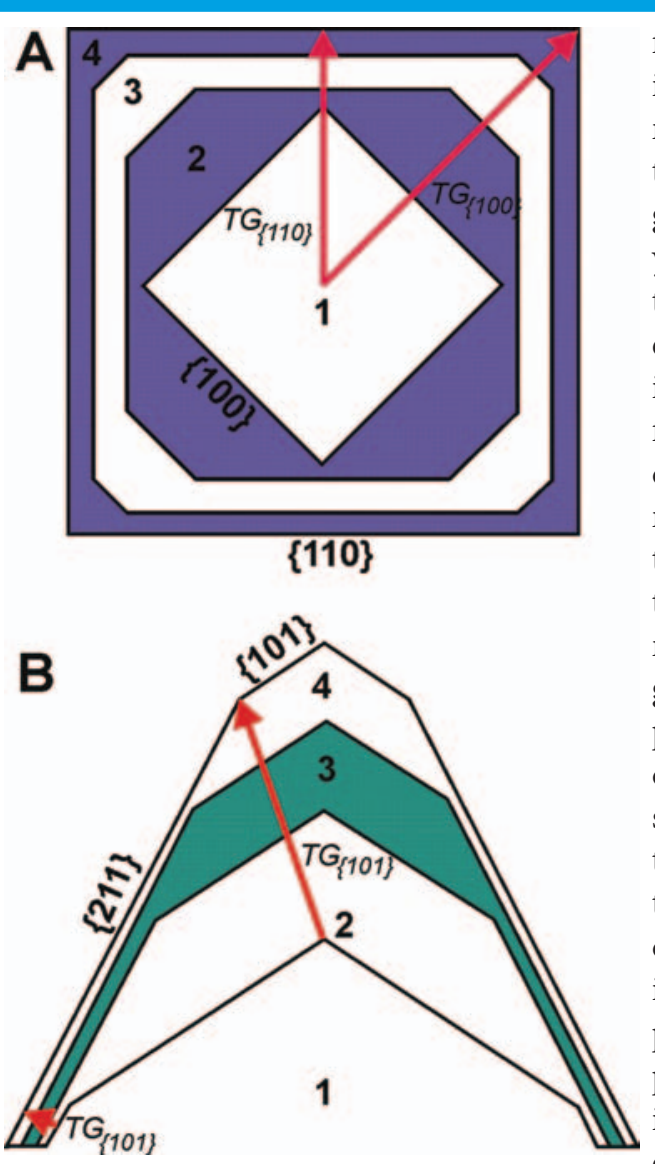

Fig. 3: Sketch illustrating the growth band measurement of the prism forms $\{100\}$ and $\{110\}$ (A) as well as the pyramidal forms $\{101\}$ and $\{211\}(B)$. Numbers denote single growth zones, whereas red arrows mark total growth (TG) of the respective forms. Total growth may be obtained by adding individual growth bands of a specific crystal form. for the detailed investigation of magmatic crystal growth. While growth-band analysis is amenable to backscattered electron imaging, any chemical factors affecting crystal development may be detected by application of WDS element analysis. The growth analysis procedure is preceded by a specific specimen preparation protocol for the zircon single crystals. Depending upon whether prism growth or pyramidal growth is studied, a cross or longitudinal section of a selected crystal is produced according to a well-defined preparation technique $^{(9)}$. The surface of the sec-

tion has to be polished perfectly to guarantee ideal analyses with the microprobe (Fig. 1).

Backscattered electron imaging, the technical setup of which is schematically illustrated in Fig. 2, is based on the principle that the number of electrons reflected from a sample correlates with the atomic mass number of elements in the sample. Hence, bright zones on the monitor indicate higher concentrations of elements with enhanced atomic mass and vice versa. For an optimum visualization of zircon crystals sectioned perpendicular or parallel to their crystallographic main axes, an accelerating voltage of 15 to $20 \mathrm{kV}$, a beam current of 30 to $40 \mathrm{nA}$ and a beam diameter of about $1 \mu \mathrm{m}$ were selected. Measurement of growth bands took place on photographs with a predefined magnification.

For a determination of possible influences of crystal chemistry on the morphological development of accessory zircon, chemical profiles using the wave-length-dispersive system (WDS) were measured. Orientation of these profiles depended upon the section type, the intensity of growth zoning, and the possible content of an inherited core, i.e. a pre-magmatic crystal fragment serving as a nucleus for crystallization. X-ray spectra were collected and analyzed for the chemical elements of interest ( $\mathrm{Zr}, \mathrm{Si}, \mathrm{U}, \mathrm{Th}, \mathrm{Hf}$, $\mathrm{Y}, \mathrm{Yb}, \mathrm{Sc}, \mathrm{P})$ using LIF, TAP and PET crystals, and appropriate

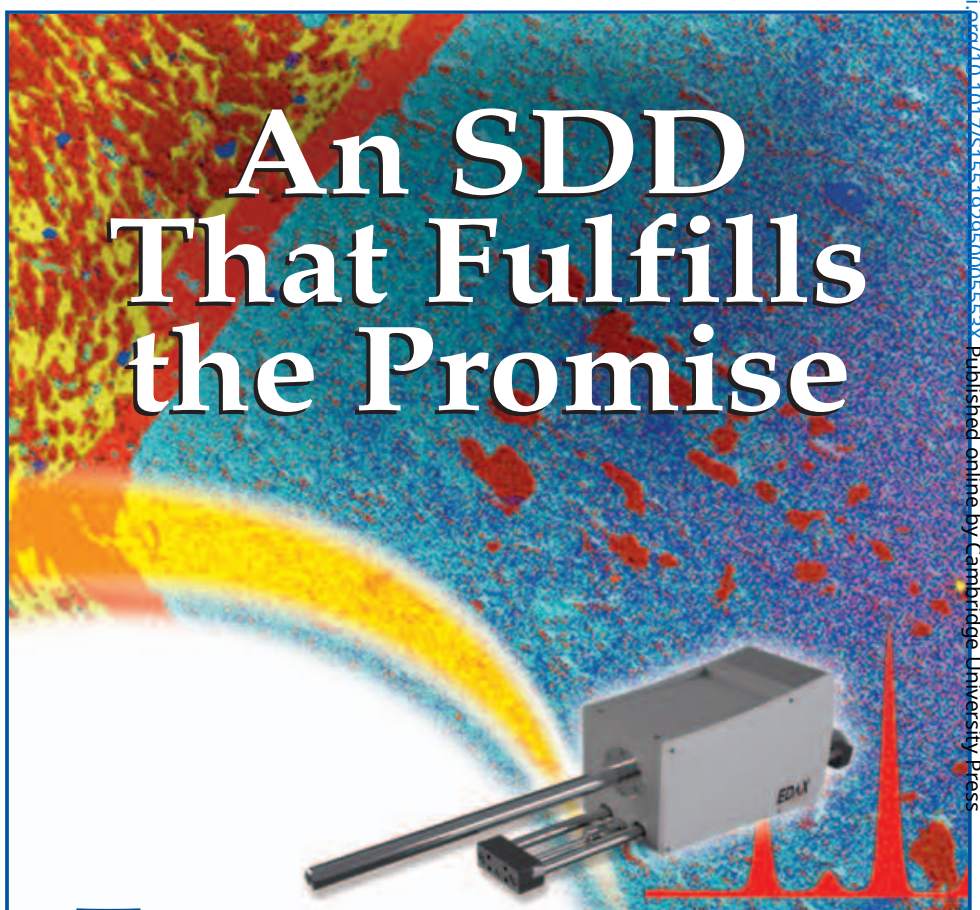

The Apollo SDD

Series - Silicon

Drift Detectors for

Unrivaled X-ray

Microanalysis

- The highest collection efficiency enabling maximum $X$-ray count collection

Superior light element performance

- $\mathrm{LN}_{2}$ free operation with rapid cool down

- Excellent peak and resolution stability over the entire dynamic range of the detector

Results with Confidence...Even Faster

With the Apollo SDD, EDAX continues to raise the performance standard that provides faster results that you can trust to be complete and accurate.

For more information on EDAX's latest product developments visit our web site at WWW.EDAX.com/NEW or call 1-201-529-4880.

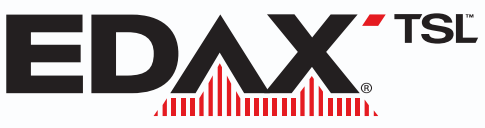

advanced microanalysis solutions

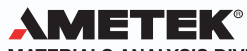

MATERIALS ANALYSIS DIVISION 


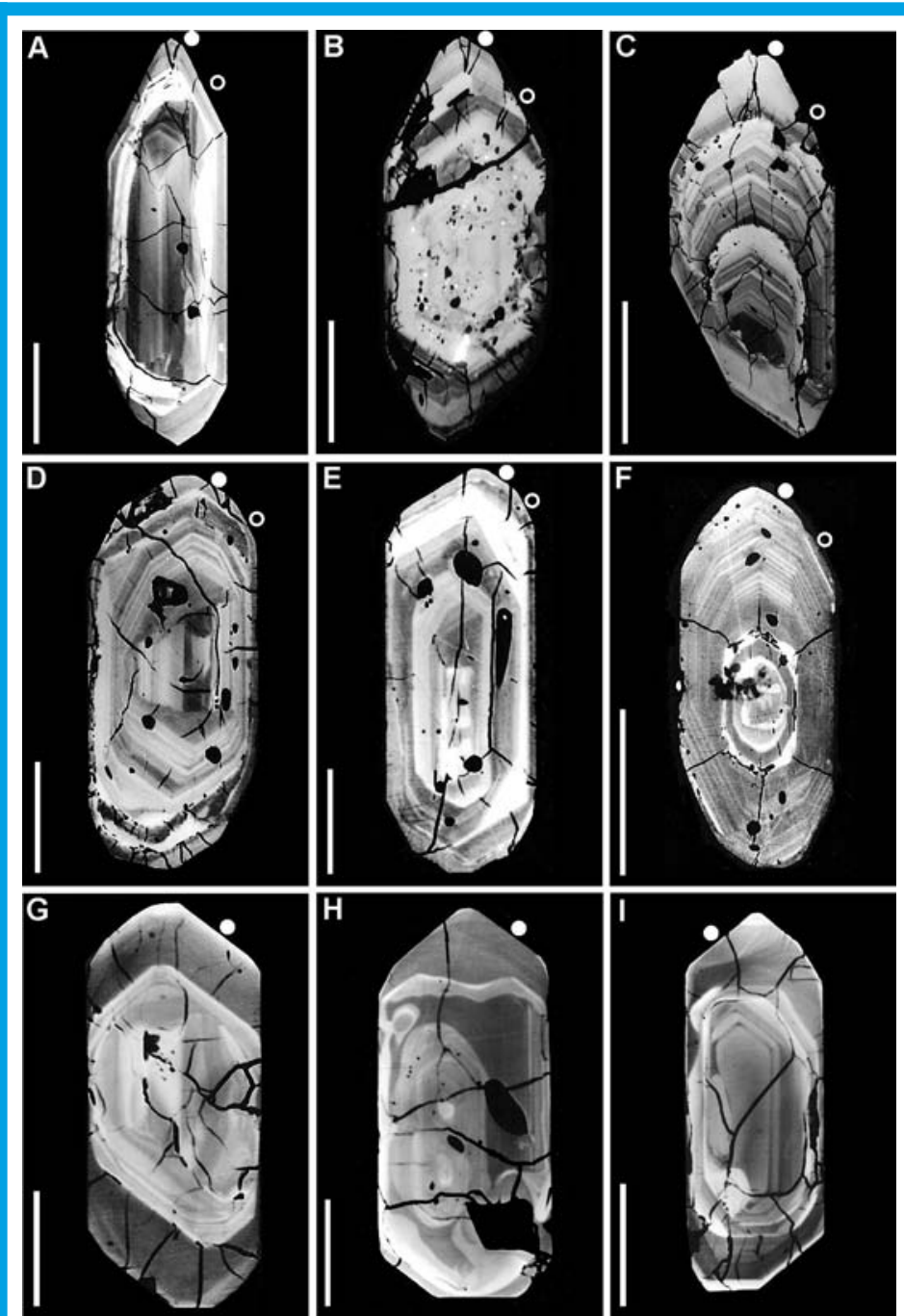

Fig. 4: Longitudinal sections of zircon crystals extracted from Al-rich granites $(A-C)$, calcalkaline granites $(D-F)$, and alkaline granites $(G-I)$. Open circles mark the steep pyramid $\{211\}$, filled circles the flat pyramid $\{101\}$ (Bars: $50 \mu \mathrm{m}$ ).

element quantification enabled by the use of oxide standards of those elements named above. For the measurement procedure, an accelerating voltage of $15 \mathrm{kV}$ as well as a beam current of 30 nA were selected.

\section{Growth-band measurement with backscattered electron imaging}

Only in rare cases growth of zircon is defined by ideal geometric growth zones, allowing an exact determination of the proportions of adjacent crystal faces at any stage of crystallization. Usually, zircon being separated from igneous rocks is characterized by very irregular growth bands, whose development is additionally affected by phenomena such as crystal corrosion and recrystallization. If an inherited core is included, crystal growth can be often subdivided into two clearly distinguishable phases, an older central phase and a younger outer phase (see example in Fig. 2). The non-ideal development of crystal morphology, however, makes a successful analysis of growth bands more difficult and therefore requires considerable crystallographic experience.

Concerning pyramidal growth of accessory zircon, longitudinal crystal sections like those exhibited in Fig. 4 were subject to an extensive growth band measurement protocol, whereby total growth (i.e. the sum of the growth zones) of the steep pyramid
$\{211\}$ and the flat pyramid $\{101\}$ were compared and processed graphically (Figs. 3, 6).

Since only main results understandable for the non-specialist should be presented here, three primary types of pyramidal growth can be distinguished in this study: 1) growth characterized by a final predominance of the steep pyramid over the flat pyramid, 2) growth resulting in an outer morphology with nearly equally sized pyramidal forms, and 3) growth, which only allows the, let's say, static development of the flat pyramid. As underlined by Fig. 6 , the first growth type preferentially occurs in Al-rich rocks, the second one in calcalkaline rocks, and the third one in high-K alkaline rocks ${ }^{(3,9)}$.

Regarding the morphological development of zircon prisms, cross sections of single crystals like those illustrated in Fig. 5 were studied in detail. Usually, measurement of prism growth may be evaluated as rather simple with respect to pyramidal growth analysis due to a better and sharper appearance of single growth zones. In this specific case, total growth of the two prism forms $\{100\}$ and $\{110\}$ were compared and, again, plotted into the respective diagram of Fig. 6. Similar to pyramidal growth analysis, three types of prism development may be summarized in the study presented here: 1) growth resulting in an extern predominance of the prism $\{110\}, 2)$ growth causing an extern zircon morphology with nearly equally sized prism forms, and 3) growth tending to the formation of crystals with a highly dominant prism $\{100\}$.

For prism growth the same chemical categorization may be applied to granitic rocks as for pyramidal growth (Fig. 4). Hence, the first growth type may be assigned to Al-rich granites, often occurring as so-called leucogranites due to their high content of bright mineral phases (feldspar, muscovite). The second growth type is normally related to calcalkaline granites and the third one
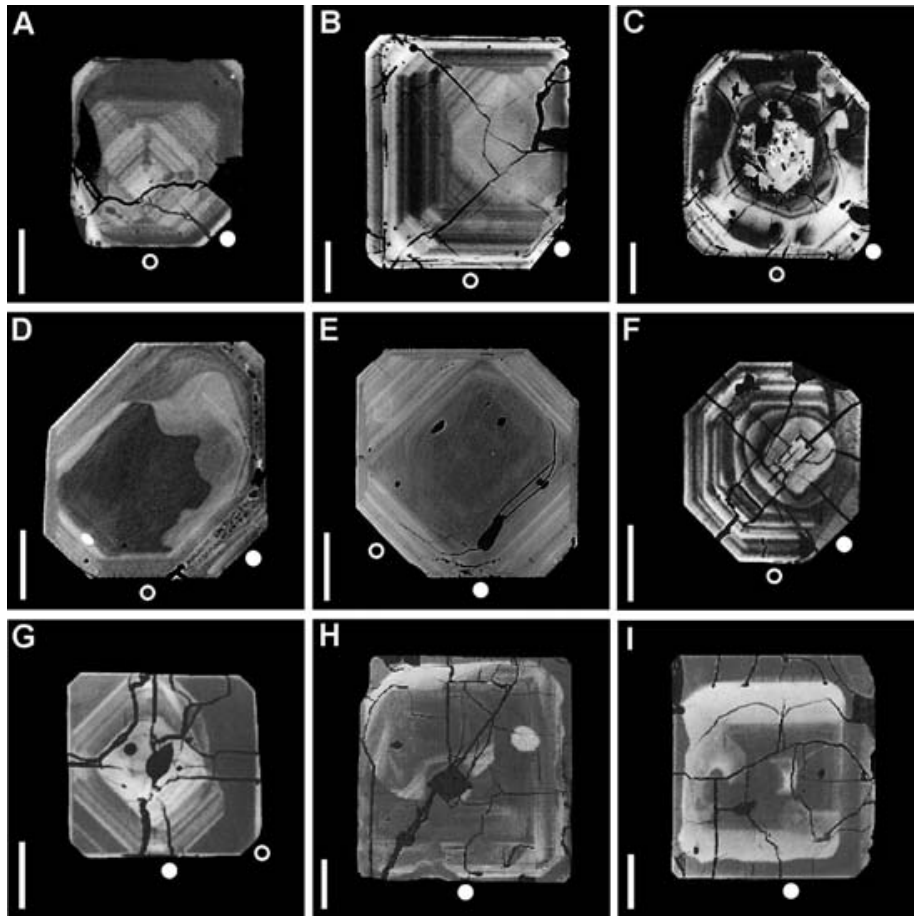

Fig. 5: Cross sections of zircon crystals extracted from Al-rich granites $(A-C)$, calcalkaline granites $(D-F)$, and high-K alkaline granites $(G-I)$. Open circles mark the prism $\{110\}$, filled circles the prism $\{100\}$ (Bars: $20 \mu \mathrm{m})$. 

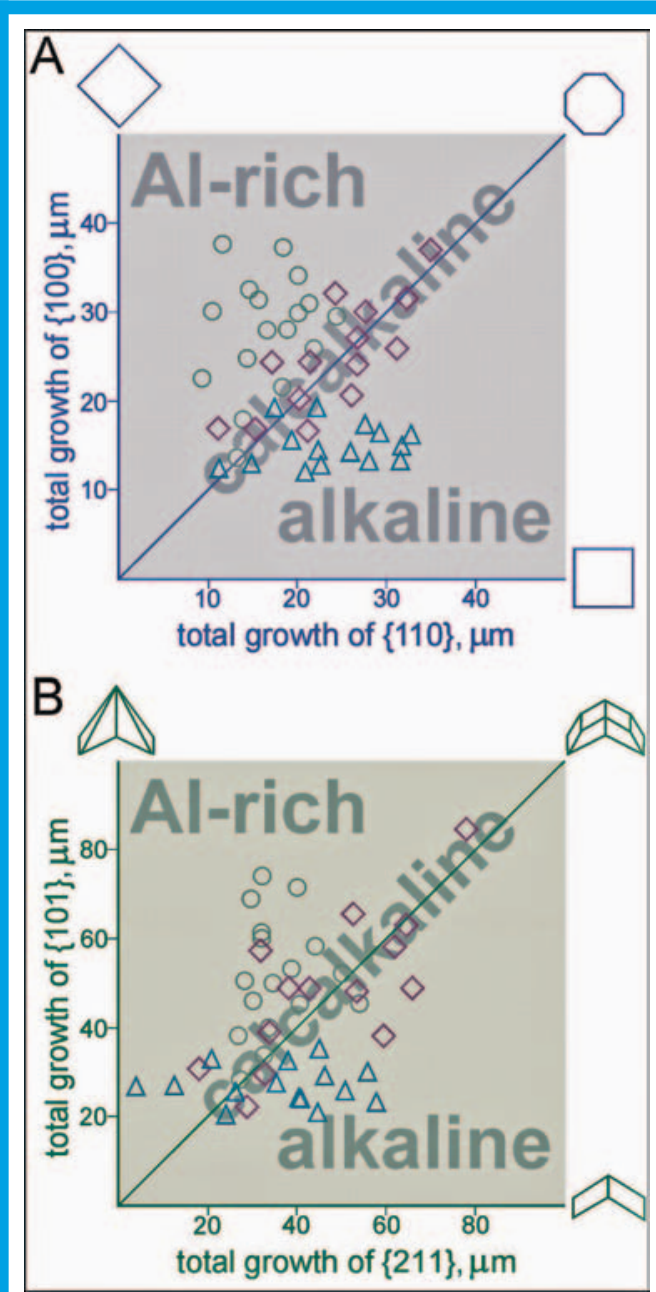

Fig. 6: Results obtained from growth band analysis of the prism forms $\{100\}$ and $\{110\}(A)$ as well as the pyramidal forms $\{101\}$ and $\{211\}$ (B). Total growth means the sum of growth bands from the beginning to the end of crystallization. Symbols: circles...Al-rich granite, diamonds... calcalkaline granite, triangles...alkaline granite. may be found in high-K alkaline granites $^{(3,9)}$.

Summing up, it can be concluded that magma chemistry represents a highly essential environmental factor influencing zircon growth significantly. By using appropriate electron-microscopic techniques, the value of zircon as a petrogenetic indicator becomes clearly noticeable.

Measurement of chemical profiles with WDS analysis

Measurement of chemical profiles were limited so far to cross sections of pre-selected zircon crystals from both Al-rich granites and alkaline granites (Fig. 7). Since the study presented here should only give a coarse overview of the electron-microscopic zircon research, profiles of the three important elements Hf, Y, and U are presented. Zircon from the Al-rich granite is often characterized by a 'switch' of the prism forms, i.e. crystallization starts with the prism form $\{100\}$, and at a middle stage of crystal growth, predominance of the prism form $\{110\}$ becomes successively increased. From a crystal-chemical point of view, this remarkable change in prism growth is caused by heavy elements, especially $U$ and Hf, blocking the growth of one prism form but having no influence on the growth of the competing prism form. In the present case, this blocking effect becomes visible in the outer bright zone of grain A in Fig. 7, where concentrations of $\mathrm{U}$ and $\mathrm{Hf}$ are increased (see profile), leading to a growth blockage of the form $\{110\}$ but an undisturbed growth of the form $\{100\}^{(3,9)}$. This results in the extern crystal morphology almost described in Fig. 5.

A more undifferentiated picture is given for the zircon crystals from alkaline granite, where the 'switch' of prism forms during growth is not available. Prism growth, however, is marked by a continuous enlargement of the form $\{100\}$, whereby bright and dark growth bands are arranged according to a regular pattern. Re-
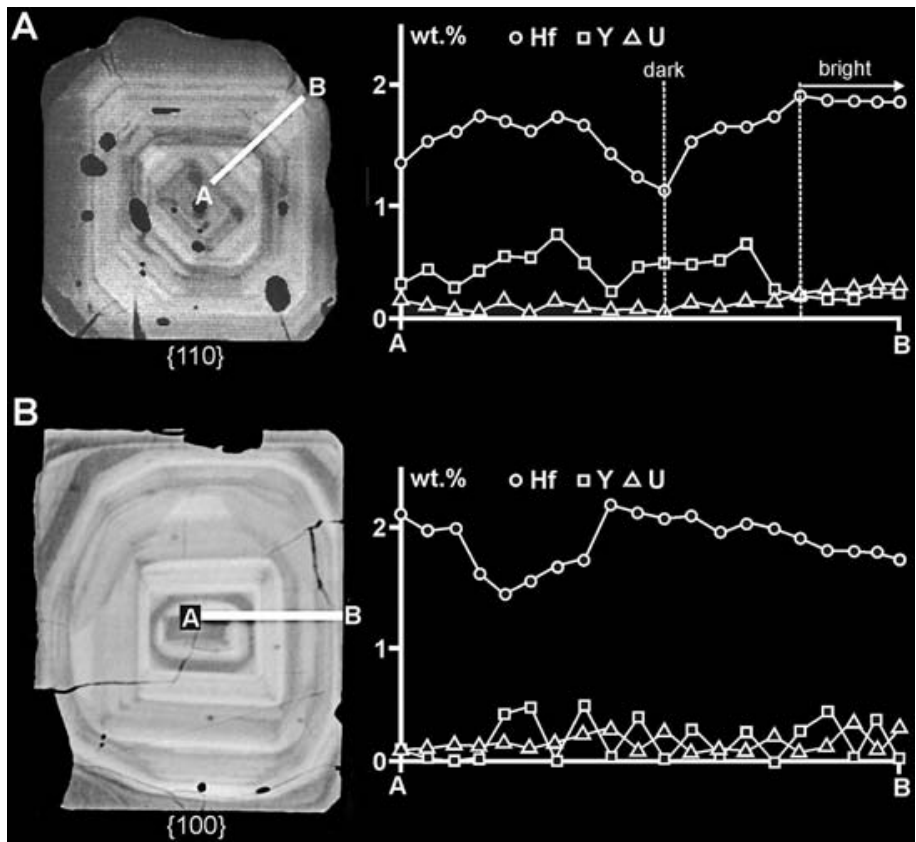

Fig. 7: Chemical profiles of the three elements $H f, Y$, and $U$ on selected cross sections of zircon crystals separated from a Al-rich granite (A) and a high-K alkaline granite (B). Profile length corresponds to $20 \mu \mathrm{m}$, respectively.

garding the chemical element profiles, $Y$ behaves rather sensitively along the growth zone pattern in the way that element concentration in bright zones is significantly increased and vice versa. The elements $\mathrm{Hf}$ and $\mathrm{U}$ do not follow any similar trend. Summing up, 'static' prism growth does not exhibit any specificities concerning element insertion into the crystal lattice.

\section{Conclusions}

As demonstrated by several examples, electron microprobe analysis of accessory zircon may be regarded as an essential tool for answering important questions in earth sciences that are not solved appropriately before now. While backscattered electron imaging provides a reliable method for studying the growth development of single zircon crystals, chemical analysis using the WDS enables the deciphering of further possible correlations between magma chemistry and the way of crystallization in the near future.

\section{References}

(1) Sunagawa, I. (1984): Growth of crystals in nature. In: Sunagawa, I. (ed.), Materials science of the Earth's interior, Terra Scientific, Tokyo, 63-15.

(2) Caruba, R. (1978): Morphologie de zircons synthétiques: corrélations pétrogénétiques. Can. Mineral. 16, 315-323.

(3) Vavra, G. (1994): Systematics of internal zircon morphology in major Variscan granitoid types. Contrib. Mineral. Petrol. 117, 331-344.

(4) Speer, J. A. (1982): Zircon. In: Ribbe, P. H. (ed.), Orthosilicates, MSA, Washington DC, 67-112.

(5) Pupin, J. P., Turco, G. (1972): Une typologie originale du zircon accessoire. Bull. Soc. Fr. Minéral Cristallogr. 95, 348-359.

(6) Pupin, J. P. (1980): Zircon and granite petrology. Contrib. Mineral. Petrol. 73, 207-220.

(7) Vavra, G. (1990): On the kinematics of zircon growth and its petrogenetic significance: a cathodoluminescence study. Contrib. Mineral. Petrol. 106, 90-99.

(8) Paterson, B. A., Stephens, W. E., Rogers, G., Williams, I. S., Hinton, R. W., Herd, D. A. (1992): The nature of zircon inheritance in 2 granite plutons. Trans. $R$. Soc. Edinburgh : Earth Sci. 83, 459-471.

(9) Sturm, R. (1999): Longitudinal and cross section of zircon: a new method for the investigation of morphological evolutional trends. Schweiz. Mineral. Petrogr. Mitt. 79, 309-316. 